\title{
Spotlight on olfactory dysfunction in Parkinson's disease
}

Mayela

Rodríguez-Violante ${ }^{1,2}$

Natalia Ospina-García ${ }^{1,2}$

Christian Pérez-Lohman ${ }^{1,2}$

Amin Cervantes-Arriaga ${ }^{1,2}$

'Movement Disorders Clinic, National Institute of Neurology and Neurosurgery, Mexico City, Mexico; ${ }^{2}$ Clinical Neurodegenerative Research Unit, National Institute of Neurology and Neurosurgery, Mexico City, Mexico

Correspondence: Mayela

Rodríguez-Violante

Movement Disorders Clinic, National Institute of Neurology and Neurosurgery, Insurgentes Sur \#3877, Col. La Fama,

14269 Mexico City, Mexico

Tel +525556063822 ext 5018

Fax +5255 5I7I 6456

Email mrodriguez@innn.edu.mx
This article was published in the following Dove Press journal:

Journal of Parkinsonism and Restless Legs Syndrome

28 June 2017

Number of times this article has been viewed

Abstract: Olfactory dysfunction is frequent in Parkinson's disease (PD). A correlation between olfactory dysfunction and the pathophysiological process of the disease has been confirmed. On the other hand, olfaction disturbances are also prevalent in other neurodegenerative diseases, and may be related to other factors such as gender, age, smoking, and trauma. Clinically, hyposmia is commonly assessed by smell identification testing. Good diagnostic accuracy has been widely reported, but differences in sensitivity and specificity due to sociocultural factors have also been reported. Since hyposmia may be present before the onset of motor symptoms, it has the potential to serve as a biomarker for the identification of subjects at risk of developing PD. Several studies have been conducted to assess the utility of smell testing as an isolated or combined biomarker for this end. Finally, severe olfactory dysfunction has been associated with faster disease progression and higher risk of cognitive decline in patients with PD. Olfactory dysfunction assessment in PD will continue to be relevant in research and clinical practice.

Keywords: Parkinson's disease, olfaction, smell identification test, biomarker

\section{Background}

Our sense of smell allows us to detect, identify, and discriminate all the diverse odors that surround us, the scent of food and beverages, the fragrance of our environment, and the scent of other people; it warns us of potentially dangerous smells such as spoiled food or dangerous fumes in the air, and can evoke autobiographic memories. ${ }^{1,2}$

Despite all of its amazing properties, the sense of smell is often neglected from medical care until it is partially or completely lost. During the last years, smell dysfunction has been associated with several neurodegenerative diseases including Parkinson's disease (PD). Hyposmia in PD has allowed to better understand the physiopathology of the disease, to improve the accuracy of clinical diagnosis, and has been proposed as a viable biomarker for the disease. The objective of this review is to highlight the current state of the art of olfactory dysfunction in PD, from both a theoretical and clinical standpoint. On this matter, this review will aid in translating basic science concepts to the day-to-day clinical practice, while providing enough background for understanding and developing new research.

\section{Basis of olfactory dysfunction in PD}

From the clinical standpoint, olfactory dysfunction is usually associated with anosmia, hyposmia, and dysosmia. Anosmia and hyposmia refer to a complete and partial loss of smell, respectively. On the other hand, identification and discrimination of 
different odors require memory and other higher order cortical interactions; an alteration in either of these processes is termed dysosmia. To better understand the role of olfactory impairment in PD, some familiarities with the olfactory system, factors affecting smell identification, and Lewy body deposition are needed.

\section{The olfactory system}

The olfactory pathway initiates in the olfactory epithelium that overlies the nasal cavity with the olfactory receptor neurons (ORNs). Their dendritic end projects to the underlying mucus; therefore, these cells are exposed to the environment. ${ }^{3,4}$ Odors bind to very specific olfactory receptor (OR) located on the ORNs. The axons of the ORNs form bundles that pierce the cribriform plate of the ethmoid bone and form the outermost layer of the olfactory bulb (OB). ${ }^{5}$ The OB is a highly intricate structure. It comprises six different layers that contain several distinct neurons, which are as follows from distal to proximal end: the olfactory nerve layer (formed by the bundle of axons that pierce the cribriform plate), the glomerular layer (where the axons of the ORNs meet the dendrites of the mitral and tufted cells), the external plexiform layer (containing tufted cells), the mitral layer (containing mitral cells), the internal plexiform layer (containing collateral axons of mitral and tufted cells), and finally the granule cell layer. ${ }^{3,4}$ Centrifugal axons from brainstem nuclei such as the locus coeruleus, nucleus basalis of Meynert, and dorsal raphe nucleus are synapses with mitral and tufted cells in the glomerular layer. ${ }^{6,7}$

Some of the axons of tufted and mitral cells reach the pyramidal cells of the anterior olfactory nucleus (AON), which in turn send their own axons to primary olfactory cortices. Some other axons of tufted and mitral cells travel directly to primary olfactory cortices; nevertheless, all these axons converge and form the olfactory tract. On the other hand, the olfactory tract divides into a median and a lateral olfactory stria. Some of these fibers decussate and reach the contralateral olfactory cortex; the fibers of the lateral stria reach the piriform cortex, the anterior cortical nucleus of the amygdala, the periamygdaloid cortex, and the entorhinal cortex. ${ }^{8}$ These regions form the primary olfactory cortex, which connects with other cortical and subcortical areas, such as the orbitofrontal cortex, the amygdala, the hypothalamus, the thalamus, and the nucleus accumbens.

Due to this widespread pathway, there are numerous medical conditions that can affect the sense of smell, which include neurological, nutritional, endocrine, infectious, and local pathological alterations. ${ }^{9}$

\section{Factors affecting olfactory functioning}

Physiological differences in smell acuity exist between men and women. Women have more neurons and glial cells than men; thus, they perform better than men in identifying odors, and this difference is maintained through all ages. ${ }^{10}$ On this matter, it is well known that olfactory abilities decline as age progresses. ${ }^{11}$ Between 65 and 80 years of age, up to $50 \%$ of the general population have a demonstrable olfactory impairment. ${ }^{12}$ In fact, a study carried out in over 2000 individuals showed that $62.5 \%$ of subjects between 80 and 97 years of age had olfactory impairment. ${ }^{13}$ There are several factors that play a role in age-related olfactory loss including changes in nasal airflow patterns and mucous composition, atrophy of the nasal epithelium, decrease in mucosal blood flow, decrements in elasticity, decline in size and number of patent foramina of the cribriform plate, decreasing number of ORs due to less mitotic activity, diminished immunologic defense mechanisms, secondary atrophy of the $\mathrm{OB}$, decreased brain weight, cortical thickness, decrements in the volume of the hippocampus, amygdala, piriform cortex and frontal poles of the brain, and diminished synthesis of neurotransmitters. ${ }^{12}$

Another relevant factor associated with olfactory dysfunction is chronic exposure to environmental agents such as air pollution, cigarette smoke, upper respiratory tract infections, nasal airway obstruction, and trauma. ${ }^{12,14}$ Air pollution deserves a special mention, since it causes significant decrements in olfactory functions even in younger people living in highly contaminated urban areas. ${ }^{15}$

\section{Alpha-synuclein pathology in the olfactory system}

Alpha-synuclein is the main component of Lewy bodies and Lewy neurites, ${ }^{16,17}$ and is considered the histopathological hallmark of PD. Lewy bodies have been found in the OB, AON, and several areas of olfactory cortices of PD patients and asymptomatic patients with incidental Lewy bodies. ${ }^{18,19}$ According to Braak's hypothesis, alpha-synuclein deposition in olfactory structures occurs before deposition in the substantia nigra. ${ }^{20-22}$ In fact, olfactory dysfunction in PD predates motor symptoms for at least 4 years, and it is closely related to the localization of alpha-synuclein pathology. ${ }^{23-27}$ Alpha-synuclein pathology appears first in the thin olfactory nerve layer, from there it reaches the glomeruli of the $\mathrm{OB}$, and then spreads through the dendrites of mitral and tufted cells. ${ }^{28}$ As already mentioned, the cortical nucleus of the amygdala receives projections from the mitral and tufted cells; in PD patients, more neural loss and Lewy body deposition are found on this area in comparison to other olfactory cortical 
areas, suggesting that these findings account for the earlier olfactory deficits in PD. ${ }^{29}$

Interestingly, $\mathrm{OB}$ volume in $\mathrm{PD}$ patients is not associated with its dysfunction. ${ }^{30,31}$

\section{Frequency of olfactory dysfunction in neurodegenerative diseases}

\section{Prevalence of PD}

The association between hyposmia and PD was first reported more than 30 years ago. ${ }^{32}$ Prevalence of olfactory dysfunction in PD is around $90 \%,{ }^{33}$ some variation may be found as a consequence of the study sample, olfactory impairment definition, or the assessing tool used.

\section{Olfactory dysfunction in other diseases}

Olfactory dysfunction is not exclusive of PD, but also can be found in several other neurodegenerative conditions including other synucleinopathies and tauopathies. Nevertheless, it has been well established that in multiple system atrophy, progressive supranuclear palsy and corticobasal degeneration olfactory function is preserved or mildly impaired, while in PD olfaction is markedly reduced.$^{34}$ In addition, significant olfactory dysfunction has been reported in Alzheimer's disease,${ }^{35}$ familial ataxias, ${ }^{36}$ incidental Lewy Body disease, ${ }^{37}$ and Huntington disease. ${ }^{38}$

\section{Assessing olfactory function in clinical practice}

Currently, multiple tests for the assessment of olfactory function are commercially available. ${ }^{39}$ Regardless of the type of smell test used, there are some recommendations that must be considered before the actual testing. First, the clinician should try to rule out pre-existing nasal disorders, upper respiratory problems, and head or face lesions. Medical history and clinical examination may be sufficient, but in some cases endoscopy or computed tomography may be necessary. ${ }^{40-42}$

Second, when trying to differentiate conductive from neural disorders it should be remembered that sensorineural anosmia is most commonly permanent, while conductive anosmia is usually intermittent. Third, cognitive assessments as well as proper identification of psychiatric and behavioral symptoms are important before the evaluation. ${ }^{41-43}$

Psychophysical tests are the most widely used for quantifying olfactory function. These tests can evaluate different functional modalities of olfaction such as odor sensitivity (i.e., threshold tests), odor discrimination, and odor identification. ${ }^{42,43}$ Smell threshold testing is based on odor detection or sensitivity; the test helps in finding the lowest concentration of an odorant perceived by a subject. Smell discrimination testing assesses the capacity of the subject to distinguish different odorants. Lastly, smell identification testing relies on the perception and correct naming of an odorant.

Most studies assessing olfaction in PD use odor identification tests. The University of Pennsylvania Smell Identification Test (UPSIT) is arguably the identification test used worldwide. It consists of 40 microencapsulated odors, which are released after scratching the surface with a pencil. The subjects are then asked to identify each odorant from a multiple choice list (four options for each smell item). ${ }^{44,45} \mathrm{~A}$ shortened version of the UPSIT is available; the Brief Smell Identification Test (B-SIT) comprises 12 items, while the Quick Smell Identification Test with only three items serves more as a screening tool.

Another widely used test in PD is the "Sniffin' sticks" (SS), a chemosensorial test based on a pen-like odordispensing device. SS extended kit can assess three qualities of olfactory function: odor threshold (N-butanol), odor discrimination (16 pairs of odorants), and odor identification (16 common odorants). ${ }^{46}$ The more commonly used version is the 16 smells test (SS-16), but a 12-screening test is also available (SS-12). Table 1 briefly describes the main smell identification tests commercially available. Conversion methods for equating scores between UPSIT, B-SIT, SS-16, and SS-12 have been recently published by Lawton et al. ${ }^{47}$

\section{Diagnostic accuracy for PD}

As mentioned previously, olfactory deficit is a common clinical sign in PD, present in $70-90 \%$ of the patients, and is one of the most noticeable non-motor features of disease. ${ }^{41,42,48}$ Moreover, several studies have showed that olfactory dysfunction can appear years prior to the onset of motor symptoms. ${ }^{23,26,41}$ Consequently, olfactory dysfunction may be useful to aid in the clinical diagnosis of PD.

Current evidence has shown that PD patients may have olfactory disturbances in any of the different functional modalities (odor detection, discrimination, and identification). ${ }^{49-52}$ However, some studies have suggested that smell identification test is more frequently affected than discrimination. ${ }^{43,50-52} \mathrm{~A}$ study using the UPSIT test reported that patients with PD had even lower scores than control subjects in an identification task in contrast to an odor sensitivity test. ${ }^{44}$

Interestingly, smell identification is not associated with the severity of the disease, disease duration, or dopaminergic 
Table I Commercially available smell identification tests

\begin{tabular}{|c|c|}
\hline Smell identification test & Description \\
\hline University of Pennsylvania Smell Identification & 40 -Item test comprised in four booklets, each containing 10 microencapsulated odors (scratch \\
\hline Test (UPSIT) & $\begin{array}{l}\text { and sniff); available in } 29 \text { languages; existing normative data for men and women, as well as } \\
\text { cutoff values for Parkinson's disease. }\end{array}$ \\
\hline Brief Smell Identification Test (B-SIT) & $\begin{array}{l}\text { I2-Item version of the UPSIT; cross-cultural test containing odors commonly known in most } \\
\text { cultures; existing normative data; several versions available; version A only available in } 10 \\
\text { languages; version B only available in English. }\end{array}$ \\
\hline Modified Brief Smell Identification Test (MB-SIT) & $\begin{array}{l}\text { Modified version of the B-SIT including intensity, pleasantness, and familiarity rating scales; } \\
\text { available in English and Spanish. }\end{array}$ \\
\hline Pocket Smell Test & $\begin{array}{l}\text { A 3-item forced-choice test used as a screening tool. There are four different versions of the } \\
\text { test depending on the odors included. }\end{array}$ \\
\hline Quick Smell Identification Test (Q-SIT) & $\begin{array}{l}\text { 3-Item (chocolate, banana, and smoke) modified version of the Pocket Smell test. It has an } \\
\text { additional option for indicating anosmia. }\end{array}$ \\
\hline Sniffin' Sticks (SS) & $\begin{array}{l}\text { Pen-like devices, similar to the felt-tip pens, filled with an odorant. The cap is removed and the } \\
\text { subjects smell the tip of the pen and then select a response from a multiple choice form (four } \\
\text { options for each pen). The most common version includes } 16 \text { pens (SS-16). }\end{array}$ \\
\hline Sniffin' Sticks Screening Test (SS-12) & A 12-pen identification test used for screening purposes. \\
\hline Sniffin' Sticks Extended Test & $\begin{array}{l}\text { This kit contains three modules: threshold test, discrimination test, and identification test. The } \\
\text { threshold test has } 48 \text { SS. }\end{array}$ \\
\hline
\end{tabular}

replacement therapy. ${ }^{41,43,49,53}$ By contrast, odor discrimination appears to be related with disease stage and severity. ${ }^{50}$

A more recent study, assessing impairment in both discrimination and identification, showed that identification tests are more useful to differentiate between controls and PD patients in comparison to discrimination tests. Using 16-item odor identification SS test, the prevalence of olfaction dysfunction was $73 \%$ with a sensitivity of $83 \%$ and specificity of $82 \%$ when using a cutoff value of $10.5 .{ }^{53}$ In addition, this study confirmed that discrimination worsens with disease duration, while identification remains unchanged. In other words, smell identification problems are common in PD, but are independent of severity of the disease, while discrimination is in fact associated with disease progression and severity. ${ }^{52}$ Another study in Mexican population using B-SIT (an abbreviated version of UPSIT) reported a sensitivity of $71.4 \%$ and specificity of $85.7 \%$ using a cutoff value of 7 for subjects $>60$ years of age, and a cutoff value of 9 for subjects $<60$ years of age. ${ }^{54}$ Conversely, the sensitivity and specificity for other smell tests in Mexican population were $82 \%$ and $66 \%$ for the SS- 16 and $77.8 \%$ and $71.2 \%$ for the UPSIT, respectively. ${ }^{55}$

A Japanese study reported that olfactory dysfunction as assessed with the Odor Stick Identification Test for Japanese for identifying subjects with PD had a sensitivity of $85.3 \%$ and specificity of $85.7 \%{ }^{56}$

The sensitivity and specificity in Brazilian population using the UPSIT has been reported to be $82.1 \%$ and $83.51 \%$, respectively, ${ }^{57}$ while using the SS the sensitivity and specificity were found to be $81.1 \%$ and $85.7 \%$, respectively. ${ }^{58}$ In
Italian population, UPSIT differentiated between PD and control subjects with $82 \%$ sensitivity and $88.2 \%$ specificity. ${ }^{59}$

The association between motor subtypes of PD and smell identification has been less studied. Iijima et al found that smell impairment was more frequent in the akinetic-rigid subtype. ${ }^{60}$ Given the different course of the disease according to the predominant motor phenotype, olfactory dysfunction may have a role as a prognosis biomarker as mentioned later in the text.

Another matter of controversy is the possible advantage of extended olfactory and/or parallel testing to improve diagnostic performance. One study assessed whether extended olfactory testing can increase diagnostic accuracy in PD patients. The authors found that a 32-item smell identification test was not better than the 16-item test. The same was true for the extended 32-item versus the 16-item odor discrimination test. Moreover, a combination of the 16-item identification test and the 16-item discrimination was not better than the 16-item identification test alone. Lastly, the combination of the 16-item identification test along with the threshold test significantly improved the diagnostic accuracy compared with the identification test alone. ${ }^{51}$

\section{Smell identification as an isolated biomarker}

There are extensive data supporting olfactory dysfunction as a feature of premotor PD. The Honolulu-Asia Aging Study, a longitudinal study following 2267 men between 71 and 95 years of age without known PD, reported an odds ratio of 5.2 for the development of PD in subjects within the lowest quartile in odor identification test after a 4-year follow-up. ${ }^{61}$ 
Another prospective study evaluating olfactory dysfunction as a premotor biomarker included 361 asymptomatic relatives of PD patients. ${ }^{26} \mathrm{After}$ being assessed for olfactory dysfunction, 40 hyposmics and 38 normosmics subject were identified; in addition, a dopamine transporter singlephoton emission computed tomography (DAT SPECT) was performed. After a 2-year follow-up, 4 of the 40 hyposmics developed PD, in comparison to none of the normosmic subjects. The risk at 5 years of developing PD in first-degree relatives of PD with olfactory dysfunction was estimated to be $12.5 \%{ }^{62}$

\section{Smell identification as a combined biomarker}

As mentioned before, there are several studies that support olfactory dysfunction as a feature of premotor PD; nevertheless, smell loss is also found in other neurodegenerative diseases. ${ }^{63,64}$ Therefore, to improve its clinical use, a combination of two or more different biomarkers may increase the reliability of smell testing.

Haugen et al reported that $97.8 \%$ of PD patients with positron emission tomography (PET) evidence of nigrostriatal denervation have impaired olfaction; ${ }^{65}$ thus, nuclear medicine neuroimaging is a useful related biomarker.

A study assessing 24 PD patients with TRODAT SPECT and UPSIT reported a strong correlation between UPSIT scores and dopamine transporter binding in the putamen. ${ }^{66}$

In the previously mentioned study of first-degree relatives of $\mathrm{PD}$, reduction of striatal binding ratios in the SPECT was found in five of hyposmic subjects; four of them developed clinical PD. These data suggest that olfactory test followed by a SPECT improves the specificity for detecting premotor $\mathrm{PD}$.

Borghammer et al evaluated the combination of DAT SPECT and olfactory test for differentiating PD from other parkinsonisms. An abnormal SPECT along with hyposmia had a positive predictive value of $97 \%$ in the PD group, while for the atypical parkinsonism group, this value was only $45 \% .{ }^{67}$ Similarly, Georgiopoulos et al compared the efficacy of the combination of DAT SPECT and B-SIT to discriminate between patients with PD from those with atypical parkinsonism. Overall, DAT imaging was more efficient than olfactory dysfunction, but the highest accuracy was achieved combining both tests. ${ }^{68}$

López-Hernández et al reported a similar diagnostic value by combining the SS-12 and hyperechogenicity of the substantia nigra assessed by transcranial duplex ultrasound. ${ }^{69}$
Although this approach is less expensive than a PET or SPECT study, ultrasound may yield more errors due to its operator-dependent nature.

Other authors have assessed the correlation between cardiac dysautonomia and hyposmia with mixed results..$^{70,71}$

In the PREDICT-PD study, Noyce et al developed an algorithm for estimating the risk of developing PD. Based on results from systematic review of the literature, they included three of the strongest risk markers of PD, which were olfactory dysfunction (UPSIT), REM sleep behavior disorder (RBD), and finger tapping speed. ${ }^{72}$ Risk scores were categorized into higher, medium, and lower risk; using this tool on 1323 subjects, incident PD over 3 years was found to have an association with the baseline risk estimate (hazard ratio $=4.39, p=0.045) .^{73}$

\section{Implications for premotor diagnosis} Role of smell testing in PD in risk subject cohorts

Theoretically, olfactory dysfunction along with other premotor biomarkers can be used to identify subjects with an increased risk of developing PD. Although currently neuroprotective treatment is not available, the proper identification of these "enriched" populations will be of great value for the development of such therapies.

The Parkinson At-risk Syndrome (PARS) study focused on the predictive value of hyposmia for identifying this type of population. The PARS study reported that the probability of having hyposmia is increased when the subject has several other non-motor symptoms, mainly constipation, depression, and RBD. ${ }^{74}$

The Parkinson's Progression Markers Initiative (PPMI) study has five different cohorts; one of these cohorts comprises prodromal subjects. The PPMI defines a prodromal subject as a person without PD but with hyposmia and/or RBD. These subjects are also assessed using motor evaluations, neuropsychiatric scales, and DAT SPECT. ${ }^{75}$

The Prospective Validation of Risk Factors for the Development of Parkinson Syndromes (PRIPS) study recruited subjects $>50$ years of age without PD; subjects were screened for hyposmia and familial history of PD. From the first 1352 subjects included, 475 had hyposmia and/or family history of the disease; so far, 8 subjects have developed incidental PD. ${ }^{76}$

The Tuebinger evaluation of Risk factors for Early detection of NeuroDegeneration (TREND) study recruited subjects $>50$ years of age without PD who underwent an initial screening for hyposmia, depression, and RBD. Subjects with a positive screening were then assessed for dysautonomia, 
subtle motor symptoms, and hyperechogenicity of the substantia nigra. Finally, a DAT SPECT was performed. ${ }^{77}$ As expected, subjects with premotor markers such as hyposmia also had a higher prevalence of other non-motor symptoms related to $\mathrm{PD}{ }^{78}$

Finally, the Progression Markers in the suspected Premotor Phase study recruited subjects from the PRIPS and TREND cohorts; main inclusion criteria for high-risk subjects included at least one of the following: a PD cardinal motor sign or two of the following markers-lifetime prevalence of depression, hyposmia, one-sided reduced arm swing, or positive family history of PD. ${ }^{79}$

In summary, assessment of olfactory dysfunction is the key in the study designs recruiting Parkinson's at-risk subjects; Table 2 shows a brief description of these studies and the role of olfactory dysfunction.

In addition, objective olfactory dysfunction is currently included in the probabilistic model of the Movement Disorder Society (MDS) Research Criteria for Prodromal Parkinson's Disease. In this model, olfactory dysfunction yields a positive likelihood ratio of $4.0 .^{80}$

\section{Clinical correlates of olfactory impairment in PD \\ Smell and cognition}

Fullard et al evaluated the relation between olfaction and cognition. They reported that lower UPSIT scores at baseline were associated with a greater rate of decline in cognition as assessed by the Montreal Cognitive Assessment. ${ }^{81}$ It has been reported that patients with severe hyposmia have an 18-fold increase in the risk for dementia within 3 years. ${ }^{82}$ Another frequent and important premotor feature is RBD. Kang et al assessed the combined effect of RBD and hyposmia on cognition and motor phenotype. They found that patients with both RBD and olfactory dysfunction were more prone to have cognitive decline; also, patients with RBD and/or hyposmia had an akinetic-rigid predominant phenotype. ${ }^{83}$ Overall, severe hyposmia appears to be a reliable marker of risk of cognitive decline in patients with PD.

\section{Smell and genetic PD}

It has been widely reported that leucine-rich repeat kinase 2 (LRRK2) mutation carriers do show an important olfactory dysfunction. Olfactory impairment is not present in healthy LRRK2 carriers, while only very mild hyposmia is found in LRRK2 PD patients. ${ }^{84-87}$

Smell testing may be useful as a supportive marker for differentiating LRRK2 PD from idiopathic PD in the absence of genetic testing.

\section{Smell and disease progression}

One last consideration is the use of olfactory dysfunction as a marker of progression, or even as a marker of the effect of potential disease-modifying or neuroprotective therapies.

Table 2 Role of olfactory dysfunction on cohort studies addressing subjects at risk of developing PD or prodromal subjects

\begin{tabular}{|c|c|c|c|}
\hline Study cohort & Population & Objective & Role of smell testing \\
\hline $\begin{array}{l}\text { Parkinson's Associated Risk Study } \\
\text { (PARS) }\end{array}$ & $\begin{array}{l}\text { Subjects aged }>60 \text { years without } \\
\text { any neurological disorder }\end{array}$ & $\begin{array}{l}\text { To evaluate specific tests as } \\
\text { predictors for increased risk for } \\
\text { PD }\end{array}$ & $\begin{array}{l}\text { The initial test for these subjects is } \\
\text { the UPSIT }\end{array}$ \\
\hline $\begin{array}{l}\text { Progression Markers in the } \\
\text { suspected Pre-motor Phase } \\
\text { (PMPP) }\end{array}$ & $\begin{array}{l}\text { Individuals at high risk of } \\
\text { developing PD were selected } \\
\text { from the PRIPS and TREND } \\
\text { cohorts }\end{array}$ & $\begin{array}{l}\text { To monitor progression of the } \\
\text { neurodegenerative process in } \\
\text { subjects in risk, subjects with } \\
\text { early PD, and controls }\end{array}$ & $\begin{array}{l}\text { Hyposmia (assessed by the SS-12) } \\
\text { was one of the inclusion criteria in } \\
\text { subjects with documented substantia } \\
\text { nigra hyperechogenicity }\end{array}$ \\
\hline $\begin{array}{l}\text { Parkinson's Progression Markers } \\
\text { Initiative (PPMI) }\end{array}$ & $\begin{array}{l}\text { Five different populations: genetic } \\
\text { cohort, de novo PD, control, } \\
\text { SWEDD, and prodromal cohort }\end{array}$ & $\begin{array}{l}\text { To verify progression markers } \\
\text { in PD }\end{array}$ & $\begin{array}{l}\text { For the prodromal cohort, subjects } \\
\text { must have at least one of the } \\
\text { following: hyposmia (assessed by } \\
\text { the UPSIT) or RBD (assessed by } \\
\text { polysomnography) }\end{array}$ \\
\hline $\begin{array}{l}\text { Prospective Validation of Risk } \\
\text { Factors for the Development of } \\
\text { Parkinson Syndromes (PRIPS) }\end{array}$ & $\begin{array}{l}\text { Subjects aged }>60 \text { years without } \\
\text { known PD }\end{array}$ & $\begin{array}{l}\text { Early detection of incident PD in } \\
\text { PD-free subjects at baseline }\end{array}$ & $\begin{array}{l}\text { Subjects underwent a three-step } \\
\text { evaluation: screening by age, } \\
\text { screening for positive family history } \\
\text { and/or hyposmia, and screening for } \\
\text { substantia nigra hyperechogenicity }\end{array}$ \\
\hline $\begin{array}{l}\text { Tuebinger evaluation of Risk } \\
\text { factors for Early detection of } \\
\text { NeuroDegeneration (TREND) }\end{array}$ & $\begin{array}{l}\text { Subjects aged }>50 \text { years with } \\
\text { either one or several of the } \\
\text { prodromal risk markers or none } \\
\text { of these markers }\end{array}$ & $\begin{array}{l}\text { To collect data of several } \\
\text { prodromal phase biomarkers in } \\
\text { subjects without PD or Alzheimer } \\
\text { disease }\end{array}$ & $\begin{array}{l}\text { Risk markers assessed include RBD, } \\
\text { hyposmia (as assessed by the SS), and } \\
\text { depression }\end{array}$ \\
\hline
\end{tabular}

Abbreviations: PD, Parkinson's disease; UPSIT, University of Pennsylvania Smell Identification Test; SS, Sniffin' sticks; SWEDD, Scan without Evidence of Dopaminergic Deficit; RBD, REM sleep behavior disorder. 
Unfortunately, odor identification in patients with idiopathic RBD or PD does not tend to worsen over time. ${ }^{88}$ Thus, serial assessment of olfactory dysfunction is currently not recommended. Nevertheless, severe olfactory dysfunction is associated with a faster disease progression. ${ }^{89}$

\section{Conclusion}

There is no doubt that olfactory dysfunction is a key nonmotor manifestation of PD. Hyposmia may be present in $70-90 \%$ of patients with PD and precedes the motor symptom onset for several years. Moreover, olfactory dysfunction has an accurate pathological correlation with the postulated rostrocaudal disease progression.

The relevance of olfactory dysfunction is such that smell loss is one of the only two non-motor symptoms considered as a supportive criterion for the diagnosis of PD according to the MDS Clinical Diagnostic Criteria for Parkinson's Disease. ${ }^{90}$ Also, hyposmia is considered as a potential marker for the identification of subjects at the prodromal stage of this disease. Olfactory dysfunction is included in the probabilistic model of the MDS Research Criteria for Prodromal Parkinson's Disease. ${ }^{80}$

For clinicians, smell identification testing is a reliable and relatively affordable method for olfaction assessment. The most commonly used smell identification tests are the UPSIT and the SS; nevertheless, it is important to consider differences in sensitivity and specificity of these tests according to cultural differences. Olfactory dysfunction in combination with other possible markers of disease progression, such as dopaminergic neuroimaging, yields a positive predictive value of $97 \%$ for differentiating PD from other parkinsonisms. Consequently, clinicians may consider olfactory tests as a routine assessment in patients with clinical suspicion of early PD and also in cases of unclassified parkinsonism.

In the near future, olfactory dysfunction may prove to be useful for the identification of subjects for neuroprotective and disease modifying therapy clinical trials.

\section{Disclosure}

MRV has received honoraria from UCB, BoehringerIngelheim, Medtronic, Teva, and Vanquish. The other authors report no other conflicts of interest in this work.

\section{References}

1. Doty RL. Olfactory dysfunction in Parkinson disease. Nat Rev Neurol. 2012;8(6):329-339.

2. Chu S, Downes JJ. Odour-evoked autobiographical memories: psychological investigations of proustian phenomena. Chem Senses. 2000;25(1):111-116.
3. Wilson RI, Mainen ZF. Early events in olfactory processing. Annu Rev Neurosci. 2006;29:163-201.

4. Benarroch EE. Olfactory system: functional organization and involvement in neurodegenerative disease. Neurology. 2010;75(12):1104-1109.

5. Duda JE. Olfactory system pathology as a model of Lewy neurodegenerative disease. J Neurol Sci. 2010;289(1-2):49-54.

6. Chen WR, Shepherd GM. The olfactory glomerulus: a cortical module with specific functions. J Neurocytol. 2005;34(3-5):353-360.

7. Gómez C, Briñón JG, Barbado MV, Weruaga E, Valero J, Alonso JR. Heterogeneous targeting of centrifugal inputs to the glomerular layer of the main olfactory bulb. J Chem Neuroanat. 2005;29(4): 238-254.

8. Brunjes PC, Illig KR, Meyer EA. A field guide to the anterior olfactory nucleus (cortex). Brain Res Brain Res Rev. 2005;50(2):305-335.

9. Schiffman SS, Graham BG. Taste and smell perception affect appetite and immunity in the elderly. Eur J Clin Nutr. 2000;54(Suppl 3): S54-S63.

10. Oliveira-Pinto AV, Santos RM, Coutinho RA, et al. Sexual dimorphism in the human olfactory bulb: females have more neurons and glial cells than males. PLoS One. 2014;9(11):e111733.

11. Doty RL, Shaman P, Applebaum SL, Giberson R, Siksorski L, Rosenberg L. Smell identification ability: changes with age. Science. 1984;226(4681):1441-1443.

12. Doty RL, Kamath V. The influences of age on olfaction: a review. Front Psychol. 2014;5:20.

13. Murphy C, Schubert CR, Cruickshanks KJ, Klein BE, Klein R, Nondahl DM. Prevalence of olfactory impairment in older adults. JAMA. 2002;288(18):2307-2312.

14. Moccia M, Picillo M, Erro R, et al. How does smoking affect olfaction in Parkinson's disease? J Neurol Sci. 2014;340(1-2):215-217.

15. Calderón-Garcidueñas L, Franco-Lira M, Henríquez-Roldán C, et al. Urban air pollution: influences on olfactory function and pathology in exposed children and young adults. Exp Toxicol Pathol. 2010;62(1):91-102.

16. Spillantini MG, Schmidt ML, Lee VM, Trojanowski JQ, Jakes R, Goedert M. Alpha-synuclein in Lewy bodies. Nature. 1997;388(6645):839-840.

17. Spillantini MG, Crowther RA, Jakes R, Hasegawa M, Goedert M. alphaSynuclein in filamentous inclusions of Lewy bodies from Parkinson's disease and dementia with Lewy bodies. Proc Natl Acad Sci USA. 1998; 95(11):6469-6473.

18. Ross GW, Abbott RD, Petrovitch H, et al. Association of olfactory dysfunction with incidental Lewy bodies. Mov Disord. 2006;21(12):2062-2067.

19. Beach TG, White CL 3rd, Hladik CL, et al. Olfactory bulb alphasynucleinopathy has high specificity and sensitivity for Lewy body disorders. Acta Neuropathol. 2009;117(2):169-174.

20. Braak H, Del Tredici K, Rüb U, de Vos RA, Jansen Steur EN, Braak E. Staging of brain pathology related to sporadic Parkinson's disease. Neurobiol Aging. 2003;24(2):197-211.

21. Braak H, Ghebremedhin E, Rüb U, Bratzke H, Del Tredici K. Stages in the development of Parkinson's disease-related pathology. Cell Tissue Res. 2004;318(1):121-134.

22. Halliday GM, McCann H. The progression of pathology in Parkinson's disease. Ann N Y Acad Sci. 2010;1184:188-195.

23. Ross GW, Petrovitch H, Abbott RD, et al. Association of olfactory dysfunction with risk for future Parkinson's disease. Ann Neurol. 2008;63(2):167-173.

24. Haehner A, Hummel T, Hummel C, Sommer U, Junghanns S, Reichmann H. Olfactory loss may be a first sign of idiopathic Parkinson's disease. Mov Disord. 2007;22(6):839-842.

25. Haehner A, Hummel T, Reichmann H. Olfactory dysfunction as a diagnostic marker for Parkinson's disease. Expert Rev Neurother. 2009;9(12): 1773-1779.

26. Ponsen MM, Stoffers D, Booij J, van Eck-Smit BL, Wolters ECh, Berendse HW. Idiopathic hyposmia as a preclinical sign of Parkinson's disease. Ann Neurol. 2004;56(2):173-181. 
27. Ponsen MM, Stoffers D, Twisk JW, Wolters ECh, Berendse HW. Hyposmia and executive dysfunction as predictors of future Parkinson's disease: a prospective study. Mov Disord. 2009;24(7):1060-1065.

28. Sengoku R, Saito Y, Ikemura M, et al. Incidence and extent of Lewy body-related alpha-synucleinopathy in aging human olfactory bulb. 2008;67(11):1072-1083.

29. Harding AJ, Stimson E, Henderson JM, Halliday GM. Clinical correlates of selective pathology in the amygdala of patients with Parkinson's disease. Brain. 2002;125(Pt 11):2431-2445.

30. Altinayar S, Oner S, Can S, Kizilay A, Kamisli S, Sarac K. Olfactory disfunction and its relation olfactory bulb volume in Parkinson's disease. Eur Rev Med Pharmacol Sci. 2014;18(23):3659-3664.

31. Hakyemez HA, Veyseller B, Ozer F, et al. Relationship of olfactory function with olfactory bulbus volume, disease duration and Unified Parkinson's disease rating scale scores in patients with early stage of idiopathic Parkinson's disease. J Clin Neurosci. 2013;20(10):1469-1470.

32. Ansari KA, Johnson A. Olfactory function in patients with Parkinson's disease. J Chronic Dis. 1975;28(9):493-497.

33. Xiao Q, Chen S, Le W. Hyposmia: a possible biomarker of Parkinson's disease. Neurosci Bull. 2014;30(1):134-140.

34. Wenning GK, Shephard B, Hawkes C, Petruckevitch A, Lees A, Quinn N. Olfactory function in atypical parkinsonian syndromes. Acta Neurol Scand. 1995;91(4):247-250.

35. Zou YM, Lu D, Liu LP, Zhang HH, Zhou YY. Olfactory dysfunction in Alzheimer's disease. Neuropsychiatr Dis Treat. 2016;12:869-875.

36. Moscovich M, Munhoz RP, Teive HA, et al. Olfactory impairment in familial ataxias. J Neurol Neurosurg Psychiatry. 2012;83(10):970-974.

37. Driver-Dunckley E, Adler CH, Hentz JG, et al; Arizona Parkinson Disease Consortium. Olfactory dysfunction in incidental Lewy body disease and Parkinson's disease. Parkinsonism Relat Disord. 2014;20(11):1260-1262.

38. Hawkes C. Olfaction in neurodegenerative disorder. Adv Otorhinolaryngol. 2006;63:133-151.

39. Katzenschlager R, Lees AJ. Olfaction and Parkinson's syndromes: its role in differential diagnosis. Curr Opin Neurol. 2004;17(4):417-423.

40. Hawkes C. Olfaction in neurodegenerative disorder. Mov Disord. 2003;18(4):364-372.

41. Doty RL, Deems DA, Stellar S. Olfactory dysfunction in parkinsonism: a general deficit unrelated to neurologic signs, disease stage, or disease duration. Neurology. 1988;38(8):1237-1244.

42. Doty RL. Olfaction in Parkinson's disease and related disorders. Neurobiol Dis. 2012;46(3):527-552.

43. Potagas C, Dellatolas G, Ziegler M, et al. Clinical assessment of olfactory dysfunction in Parkinson's disease. Mov Disord. 1998;13(3):394-399.

44. Doty RL, Shaman P, Dann M. Development of the University of Pennsylvania Smell Identification Test: a standardized microencapsulated test of olfactory function. Physiol Behav. 1984;32(3):489-502.

45. Doty RL, Shaman P, Kimmelman CP, Dann MS. University of Pennsylvania Smell Identification Test: a rapid quantitative olfactory function test for the clinic. Laryngoscope. 1984;94(2 Pt 1):176-178.

46. Hummel T, Sekinger B, Wolf SR, Pauli E, Kobal G. 'Sniffin' sticks': olfactory performance assessed by the combined testing of odor identification, odor discrimination and olfactory threshold. Chem Senses. 1997;22(1):39-52

47. Lawton M, Hu MT, Baig F, et al. Equating scores of the University of Pennsylvania Smell Identification Test and Sniffin' Sticks test in patients with Parkinson's disease. Parkinsonism Relat Disord. 2016;33:96-101.

48. Doty RL, Bromley SM, Stern MB. Olfactory testing as an aid in the diagnosis of Parkinson's disease: development of optimal discrimination criteria. Neurodegeneration. 1995;4(1):93-97.

49. Doty RL, Stern MB, Pfeiffer C, Gollomp SM, Hurtig HI. Bilateral olfactory dysfunction in early stage treated and untreated idiopathic Parkinson's disease. J Neurol Neurosurg Psychiatry. 1992;55(2):138-142.

50. Tissingh G, Berendse HW, Bergmans P, et al. Loss of olfaction in de novo and treated Parkinson's disease: possible implications for early diagnosis. Mov Disord. 2001;16(1):41-46.
51. Boesveldt S, Verbaan D, Knol DL, et al. A comparative study of odor identification and odor discrimination deficits in Parkinson's disease. Mov Disord. 2008;23(14):1984-1990.

52. Boesveldt S, de Muinck Keizer RJ, Knol DL, Wolters ECh, Berendse HW. Extended testing across, not within, tasks raises diagnostic accuracy of smell testing in Parkinson's disease. Mov Disord. 2009;24(1):85-90.

53. Hawkes CH, Shephard BC, Daniel SE. Olfactory dysfunction in Parkinson's disease. J Neurol Neurosurg Psychiatry. 1997;62(5):436-446.

54. Rodríguez-Violante M, Lees AJ, Cervantes-Arriaga A, Corona T, Silveira-Moriyama L. Use of smell test identification in Parkinson's disease in Mexico: a matched case-control study. Mov Disord. 2011;26(1):173-176.

55. Rodríguez-Violante M, Gonzalez-Latapi P, Camacho-Ordoñez A, Martínez-Ramírez D, Morales-Briceño H, Cervantes-Arriaga A. Comparing the accuracy of different smell identification tests in Parkinson's disease: relevance of cultural aspects. Clin Neurol Neurosurg. 2014;123:9-14.

56. Miyamoto T, Miyamoto M, Iwanami M, Suzuki K, Inoue Y, Hirata K. Odor identification test as an indicator of idiopathic REM sleep behavior disorder. Mov Disord. 2009;24(2):268-273.

57. Silveira-Moriyama L, Carvalho Mde J, Katzenschlager R, et al. The use of smell identification tests in the diagnosis of Parkinson's disease in Brazil. Mov Disord. 2008;23(16):2328-2334.

58. Santin R, Fonseca VF, Bleil CB, Rieder CR, Hilbig A. Olfactory function and Parkinson's disease in Southern Brazil. Arq Neuropsiquiatr. 2010;68(2):252-257.

59. Picillo M, Pellecchia MT, Erro R, et al. The use of University of Pennsylvania Smell Identification Test in the diagnosis of Parkinson's disease in Italy. Neurol Sci. 2014;35(3):379-383.

60. Iijima M, Kobayakawa T, Saito S, et al. Differences in odor identification among clinical subtypes of Parkinson's disease. Eur J Neurol. 2011;18(3):425-429.

61. Abbott RD, Ross GW, White LR, et al. Environmental, life-style, and physical precursors of clinical Parkinson's disease: recent findings from the Honolulu-Asia Aging Study. J Neurol. 2003;250(Suppl 3): III30-III39.

62. Ponsen MM, Stoffers D, Wolters ECh, Booij J, Berendse HW. Olfactory testing combined with dopamine transporter imaging as a method to detect prodromal Parkinson's disease. J Neurol Neurosurg Psychiatry. 2010;81(4):396-399.

63. Serby M, Larson P, Kalkstein D. The nature and course of olfactory deficits in Alzheimer's disease. Am J Psychiatry. 1991;148(3):357-360.

64. Mesholam RI, Moberg PJ, Mahr RN, Doty RL. Olfaction in neurodegenerative disease: a meta-analysis of olfactory functioning in Alzheimer's and Parkinson's diseases. Arch Neurol. 1998;55(1):84-90.

65. Haugen J, Müller ML, Kotagal V, et al. Prevalence of impaired odor identification in Parkinson disease with imaging evidence of nigrostriatal denervation. J Neural Transm (Vienna). 2016;123(4):421-424.

66. Siderowf A, Newberg A, Chou KL, et al. [99mTc]TRODAT-1 SPECT imaging correlates with odor identification in early Parkinson disease. Neurology. 2005;64(10):1716-1720.

67. Borghammer P, Knudsen K, Østergaard K, et al. Combined DaT imaging and olfactory testing for differentiating parkinsonian disorders. Int J Clin Pract. 2014;68(11):1345-1351.

68. Georgiopoulos C, Davidsson A, Engström M, Larsson EM, Zachrisson $\mathrm{H}$, Dizdar N. The diagnostic value of dopamine transporter imaging and olfactory testing in patients with parkinsonian syndromes. J Neurol. 2015;262(9):2154-2163.

69. López-Hernández N, García-Escrivá A, Shalabi Benavent M. Diagnostic value of combined assessment of olfaction and sustantia nigra hyperechogenicity for Parkinson's disease. Neurología. 2015;30(8):496-501.

70. Mizutani Y, Nakamura T, Okada A, et al. Hyposmia and cardiovascular dysautonomia correlatively appear in early-stage Parkinson's disease. Parkinsonism Relat Disord. 2014;20(5):520-524.

71. Navarro-Otano J, Gaig C, Muxi A, et al. 123I-MIBG cardiac uptake, smell identification and 123I-FP-CIT SPECT in the differential diagnosis between vascular parkinsonism and Parkinson's disease. Parkinsonism Relat Disord. 2014;20(2):192-197. 
72. Noyce AJ, Bestwick JP, Silveira-Moriyama L, et al. PREDICT-PD: identifying risk of Parkinson's disease in the community: methods and baseline results. J Neurol Neurosurg Psychiatry. 2014;85(1):31-37.

73. Noyce AJ, R'Bibo L, Peress L, et al. PREDICT-PD: an online approach to prospectively identify risk indicators of Parkinson's disease. $\mathrm{Mov}$ Disord. 2017;32(2):219-226.

74. Siderowf A, Jennings D, Eberly S, et al. Impaired olfaction and other prodromal features in the Parkinson At-Risk Syndrome Study. Mov Disord. 2012;27(3):406-412.

75. Parkinson Progression Marker Initiative. The Parkinson Progression Marker Initiative (PPMI). Prog Neurobiol. 2011;95(4):629-635.

76. Berg D, Godau J, Seppi K, et al. The PRIPS study: screening battery for subjects at risk for Parkinson's disease. Eur J Neurol. 2013;20(1):102-108.

77. Berg D. Is pre-motor diagnosis possible? The European experience. Parkinsonism Relat Disord. 2012;18(Suppl 1):S195-S198.

78. Gaenslen A, Wurster I, Brockmann K, et al. Prodromal features for Parkinson's disease - baseline data from the TREND study. Eur J Neurol. 2014;21(5):766-772.

79. Liepelt-Scarfone I, Gauss K, Maetzler W, et al. Evaluation of progression markers in the premotor phase of Parkinson's disease: the progression markers in the premotor phase study. Neuroepidemiology. 2013;41(3-4):174-182.

80. Berg D, Postuma RB, Adler CH, et al. MDS research criteria for prodromal Parkinson's disease. Mov Disord. 2015;30(12):1600-1611.

81. Fullard ME, Tran B, Xie SX, et al. Olfactory impairment predicts cognitive decline in early Parkinson's disease. Parkinsonism Relat Disord. 2016;25:45-51.
82. Baba T, Kikuchi A, Hirayama K, et al. Severe olfactory dysfunction is a prodromal symptom of dementia associated with Parkinson's disease: a 3 year longitudinal study. Brain. 2012;135(Pt 1):161-169.

83. Kang SH, Lee HM, Seo WK, Kim JH, Koh SB. The combined effect of REM sleep behavior disorder and hyposmia on cognition and motor phenotype in Parkinson's disease. J Neurol Sci. 2016;368: 374-378.

84. Johansen KK, Warø BJ, Aasly JO. Olfactory dysfunction in sporadic Parkinson's Disease and LRRK2 carriers. Acta Neurol Scand. 2014;129(5):300-306.

85. Saunders-Pullman R, Stanley K, Wang C, et al. Olfactory dysfunction in LRRK2 G2019S mutation carriers. Neurology. 2011;77(4): 319-324.

86. Silveira-Moriyama L, Guedes LC, Kingsbury A, et al. Hyposmia in G2019S LRRK2-related parkinsonism: clinical and pathologic data Neurology. 2008;71(13):1021-1026.

87. Cao M, Gu ZQ, Li Y, et al. Olfactory dysfunction in Parkinson's disease patients with the LRRK2 G2385R variant. Neurosci Bull. 2016;32(6):572-576.

88. Iranzo A, Serradell M, Vilaseca I, et al. Longitudinal assessment of olfactory function in idiopathic REM sleep behavior disorder. Parkinsonism Relat Disord. 2013;19(6):600-604.

89. Cavaco S, Gonçalves A, Mendes A, et al. Abnormal Olfaction in Parkinson's disease is related to faster disease progression. Behav Neurol. 2015;2015:976589.

90. Postuma RB, Berg D, Stern M, et al. MDS clinical diagnostic criteria for Parkinson's disease. Mov Disord. 2015;30(12):1591-1601.
Journal of Parkinsonism and Restless Legs Syndrome

\section{Publish your work in this journal}

Journal of Parkinsonism and Restless Legs Syndrome is an online, open access, peer-reviewed journal. The journal publishes review articles, historical reviews, original research articles, case reports, letters to the editor, clinical teaching cases, neuroradiology highlights, neuropathology highlights, neuropsychiatry highlights, autobiographies, conference

\section{Dovepress}

proceedings, abstracts and book reviews. The manuscript management system is completely online and includes a very quick and fair peerreview system, which is all easy to use. Visit http://www.dovepress.com/ testimonials.php to read real quotes from published authors. 